\title{
COPD and acute myocardial infarction
}

\author{
Laurien Goedemans, Jeroen J. Bax and Victoria Delgado
}

Affiliation: Dept of Cardiology, Leiden University Medical Centre, Leiden, The Netherlands.

Correspondence: Jeroen J Bax, Dept of Cardiology, Heart Lung Centre, Albinusdreef 2, 2300 RC Leiden, The Netherlands. E-mail: J.J.Baxalumc.nl

@ERSpublications

Patients with COPD carry an increased risk of acute myocardial infarction with increased risk of adverse events at follow-up. Both echocardiography and advanced imaging techniques could play a pivotal role in risk stratification in patients with COPD. http://bit.ly/2E5nXk4

Cite this article as: Goedemans L, Bax JJ, Delgado V. COPD and acute myocardial infarction. Eur Respir Rev 2020; 29: 190139 [https://doi.org/10.1183/16000617.0139-2019].

ABSTRACT COPD is strongly associated with cardiovascular disease, in particular acute myocardial infarction (AMI). Besides shared risk factors, COPD-related factors, such as systemic inflammation and hypoxia, underlie the pathophysiological interaction between COPD and AMI. The prevalence of COPD amongst AMI populations ranges from $7 \%$ to $30 \%$, which is possibly even an underestimation due to underdiagnoses of COPD in general. Following the acute event, patients with COPD have an increased risk of mortality, heart failure and arrhythmias during follow-up. Adequate risk stratification can be performed using various imaging techniques, evaluating cardiac size and function after AMI. Conventional imaging techniques such as echocardiography and cardiac magnetic resonance imaging have already indicated impaired cardiac function in patients with COPD without known cardiovascular disease. Advanced imaging techniques such as speckle-tracking echocardiography and T1 mapping could provide more insight into cardiac structure and function after AMI and have proven to be of prognostic value. Future research is required to better understand the impact of AMI on patients with COPD in order to provide effective secondary prevention. The present article summarises the current knowledge on the pathophysiologic factors involved in the interaction between COPD and AMI, the prevalence and outcomes of AMI in patients with COPD and the role of imaging in the acute phase and risk stratification after AMI in patients with COPD.

\section{Introduction}

COPD is a clinical syndrome characterised by chronic respiratory symptoms, structural pulmonary abnormalities, impaired lung function (mainly progressive airflow limitation with poor reversibility) or any combination of these [1]. In 2010, more than 300 million people were estimated to suffer from this disease worldwide and it has become the third leading cause of death [2]. Although COPD was originally thought to merely affect the airways and lungs, the attention of research has been shifted towards the high prevalence of cardiovascular disease in patients with COPD [3]. Up to one-third of deaths in COPD patients can be attributed to a cardiovascular cause, illustrating the major impact of this comorbidity [4]. In particular, a strong association between COPD and acute myocardial infarction (AMI) has been emphasised and the need for adequate risk stratification in this population has been recognised as an unmet clinical need.

Identification of patients at risk of adverse events after AMI is frequently performed with cardiac imaging $[5,6]$. Echocardiography permits early assessment of left and right ventricular size and function, as surrogates of cardiac damage in the acute phase. Emerging advanced echocardiographic techniques such as speckle-tracking strain imaging enable characterisation of myocardial mechanics (strain and mechanical activation time dispersion), which have been associated with hard end-points, such as all-cause and

Provenance: Submitted article, peer reviewed.

Received: 10 Oct 2019 | Accepted after revision: 06 Dec 2019

Copyright CERS 2020. This article is open access and distributed under the terms of the Creative Commons Attribution Non-Commercial Licence 4.0. 
cardiac mortality, heart failure hospitalisation and ventricular arrhythmias [7, 8]. Additionally, cardiac magnetic resonance imaging (MRI) provides more information on tissue characterisation, which is useful to predict future cardiac remodelling and development of arrhythmias [9]. The present article reviews: 1) the pathophysiologic factors involved in the interaction between COPD and AMI; 2) the prevalence and outcomes of AMI in patients with COPD; and 3) the role of imaging in the acute phase and risk stratification after AMI in patients with COPD.

\section{AMI in patients with COPD \\ Mechanisms}

Several pathological mechanisms underlie the relationship between COPD and ischaemic heart disease. First, COPD and ischaemic heart disease share common risk factors, of which smoking and increasing age are most important. Moreover, the prevalence of other cardiovascular risk factors such as diabetes and hypertension seems to be higher in COPD patients compared to healthy individuals [10]. Besides shared risk factors, COPD specific characteristics are important features in the interaction with ischaemic heart disease. Although COPD is primarily characterised by local inflammation of the lungs, a spill-over to systemic inflammation has been shown in previous studies by increased levels of proteins in the acute phase (i.e. interleukin-6, C-reactive protein and fibrinogen) [11, 12]. These factors are involved in the atherosclerotic process, inducing plaque formation and growth. Another consequence of systemic inflammation in patients with COPD is an increased platelet count and reactivity, increasing the risk of thrombotic events. Moreover, increased levels of coagulation factors are reported in patients with COPD, resulting in higher thrombin levels [13]. In addition, high levels of matrix metalloproteinases (MMPs) have been reported, which increase the risk of atherosclerotic plaque formation, destabilisation and rupture, thrombus formation and increased arterial stiffness [14]. At follow-up, increased levels of MMPs have been related to left ventricular (LV) remodelling after AMI [15]. Furthermore, COPD-related hypoxia has been associated with activation of the renin-angiotensin system, leading to reduced renal blood flow and peripheral vasoconstriction and to increased oxidative stress, which eventually increases the risk of AMI. A schematic overview of the complex interaction between COPD and ischaemic heart disease based on current knowledge is shown in figure 1.

\section{Prevalence}

In previous literature, the prevalence of COPD in study populations consisting of patients with AMI ranges between $7 \%$ and $28 \%$ [16-24]. These studies use different definitions for the diagnosis of COPD, leading to variable prevalence and limited generalisability. In the few studies performing standardised pulmonary functional tests in patients with coronary artery disease, the prevalence of COPD was as much as $30 \%$ and the majority of the patients were newly diagnosed [25-27]. Therefore, it is likely that the prevalence of COPD in patients with AMI is underestimated in most registries, due to a large number of undiagnosed patients. In a UK registry of more than 1 million patients (among those 29870 patients had COPD) attending primary care facilities, the prevalence of AMI was 3.5-times higher in COPD patients

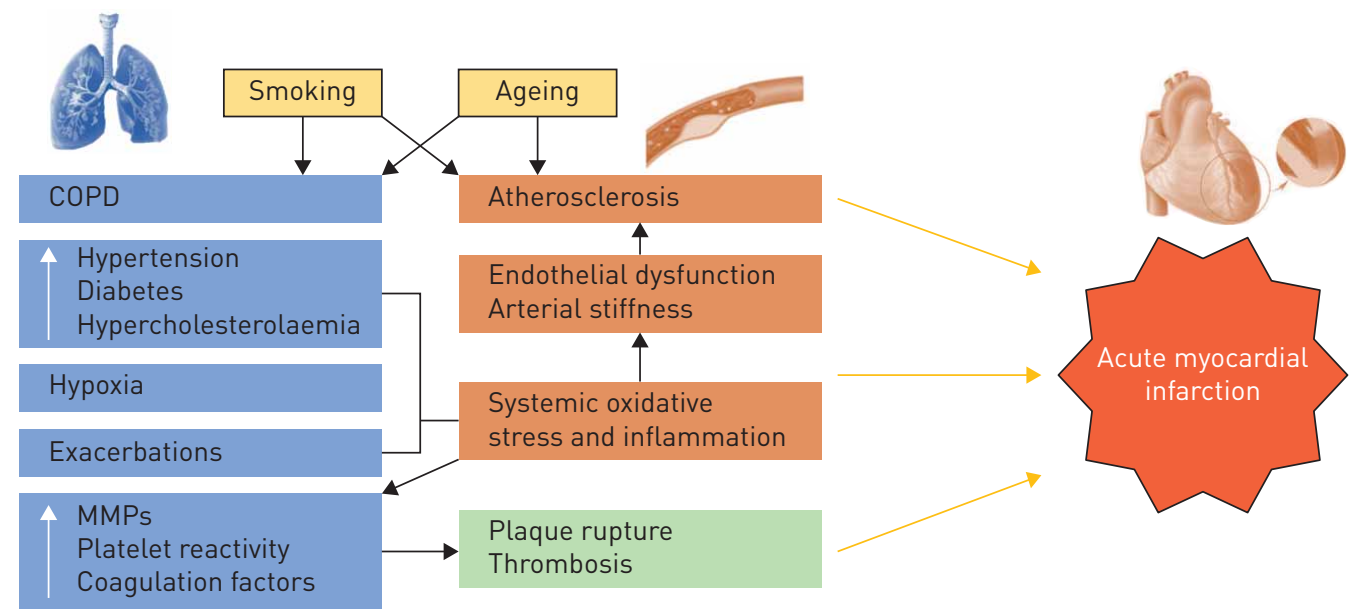

FIGURE 1 Schematic overview of the mechanisms involved in the interaction between COPD and acute myocardial infarction. Several COPD-related characteristics lead to systemic inflammation and oxidative stress, originating in atherosclerosis and increasing thrombogenic factors. Altogether, this cascade increases the risk of plaque rupture and thrombosis resulting in acute myocardial infarction. MMP: matrix metalloproteinase. 
compared to patients without COPD (hazard ratio (95\% CI) 3.53 (3.02-4.13)) [28]. A similar study performed by SCHNEIDER et al. [29] followed 35772 COPD patients from the moment of COPD diagnosis and an equal number of non-COPD patients for incident cardiovascular disease during follow-up. The relative risk estimate for incident AMI was 1.40-fold higher among COPD patients compared to non-COPD patients [29]. This relative risk increased up to 3.00 (95\% CI 1.53-5.86) for patients with severe COPD [29].

\section{Influence of acute exacerbations}

COPD is often accompanied by recurrent episodes of acute exacerbation, mostly caused by viral respiratory infections and leading to hospital admissions [30]. Acute exacerbations of COPD lead to an increased systemic inflammatory response, thereby increasing the risk of cardiovascular events through some of the pathways mentioned previously [12,31]. Previous studies in COPD patients admitted for acute exacerbation, showed increased levels of troponin $\mathrm{T}$ in a considerable part of the study population [32, 33]. However, not all those patients had an AMI. In a Chinese study, WANG et al. [34] proposed a new cut-off value for high sensitive troponin $\mathrm{T}$ to define AMI in COPD patients presenting with acute exacerbation. A cut-off value of $60.5 \mathrm{ng} \cdot \mathrm{L}^{-1}$ was proposed to diagnose AMI in this patient group, which is substantially higher compared to the normal reference population $\left(14 \mathrm{ng} \cdot \mathrm{L}^{-1}\right)$ [34]. However, this cut-off value has not been validated in other studies. Moreover, McAllister et al. [35] demonstrated that 24 (10\%) patients admitted for COPD exacerbation had increased troponin levels, of whom 20 (8.3\%; 95\% CI 5.1-12.5\%) also had chest pain and/ or ECG changes meeting the criteria for AMI. It is thought that most of these AMI events are type 2 AMIs (oxygen supply-demand imbalance) induced by tachycardia, hypoxia and an increased afterload [35]. Interestingly, in 88 patients admitted for acute exacerbation of COPD with elevated troponin I levels, invasive coronary angiography demonstrated significant coronary artery disease in $67 \%$, and in $38.6 \%$ percutaneous coronary intervention was performed [36]. The patients requiring percutaneous intervention had significantly worse LV function and more frequent ST-segment depression on ECG, although in 23 patients requiring intervention, these echocardiographic and ECG indices of ischaemia were absent [36]. This study indicates that not only type 2 AMI occurs in COPD patients with acute exacerbation and elevated troponin levels. However, the value and interpretation of elevated troponin levels in patients presenting with acute exacerbation of COPD remains a subject of debate. Further research to provide a diagnostic strategy in these patients is warranted.

The risk of AMI is increased in COPD patients not only during admission for acute exacerbations but also during follow-up. A study by CAMPO et al. [32], including COPD patients admitted with an acute exacerbation, demonstrated that elevated troponin $\mathrm{T}$ levels during admission tripled the risk of nonfatal AMI during follow-up and doubled the risk of cardiovascular death compared to patients without elevated troponin levels. A similar trend has been described in stable patients with moderate COPD and coexisting cardiovascular disease or increased cardiovascular risk [37]. In a substudy of the Study to Understand Morbidity and Mortality (SUMMIT), patients with the highest quintile of troponin I obtained before randomisation $\left(\geqslant 7.7 \mathrm{ng} \cdot \mathrm{L}^{-1}\right)$ had a $>3.5$-times higher risk of a composite cardiovascular event compared to patients within the lowest quintile $\left(<2.3 \mathrm{ng} \cdot \mathrm{L}^{-1}\right)$ (HR (95\% CI) 3.67 (1.33-10.13), p=0.012) [37].

\section{Outcomes after AMI in patients with COPD Mortality}

Prognosis of patients with COPD after AMI is markedly worse compared to patients without COPD, both during short- and long-term follow-up (table 1). Particularly, all-cause mortality rates are significantly higher after correcting for known prognostic factors and smoking. In a large population-based registry in the UK, including 34019 COPD patients and 266142 patients without COPD, the 6-month mortality rates were significantly higher among COPD patients with non-ST-segment elevation myocardial infarction (non-STEMI) and ST-segment elevation myocardial infarction (STEMI) compared to non-COPD patients (adjusted HR (95\% CI) $1.26(1.17-1.35)$ and HR 1.25 (1.11-1.41) for non-STEMI and STEMI, respectively) [20]. These results were confirmed in subsequent studies reporting double mortality rates for COPD patients compared to patients without COPD at long follow-up (table 1) [16, 21, 39].

\section{Heart failure}

Although it is known that COPD patients have an increased risk of heart failure development, only a few studies address heart failure hospitalisation after AMI in this subgroup of patients. A substudy of the Valsartan in Acute Myocardial Infarction Trial (VAILANT) including 1258 COPD and 13445 non-COPD patients, demonstrated that COPD was an independent predictor of heart failure hospitalisation during follow-up (HR (95\% CI) 1.19 (1.05-1.34)) [19] 
TABLE 1 Studies assessing the outcomes of patients with COPD after acute myocardial infarction

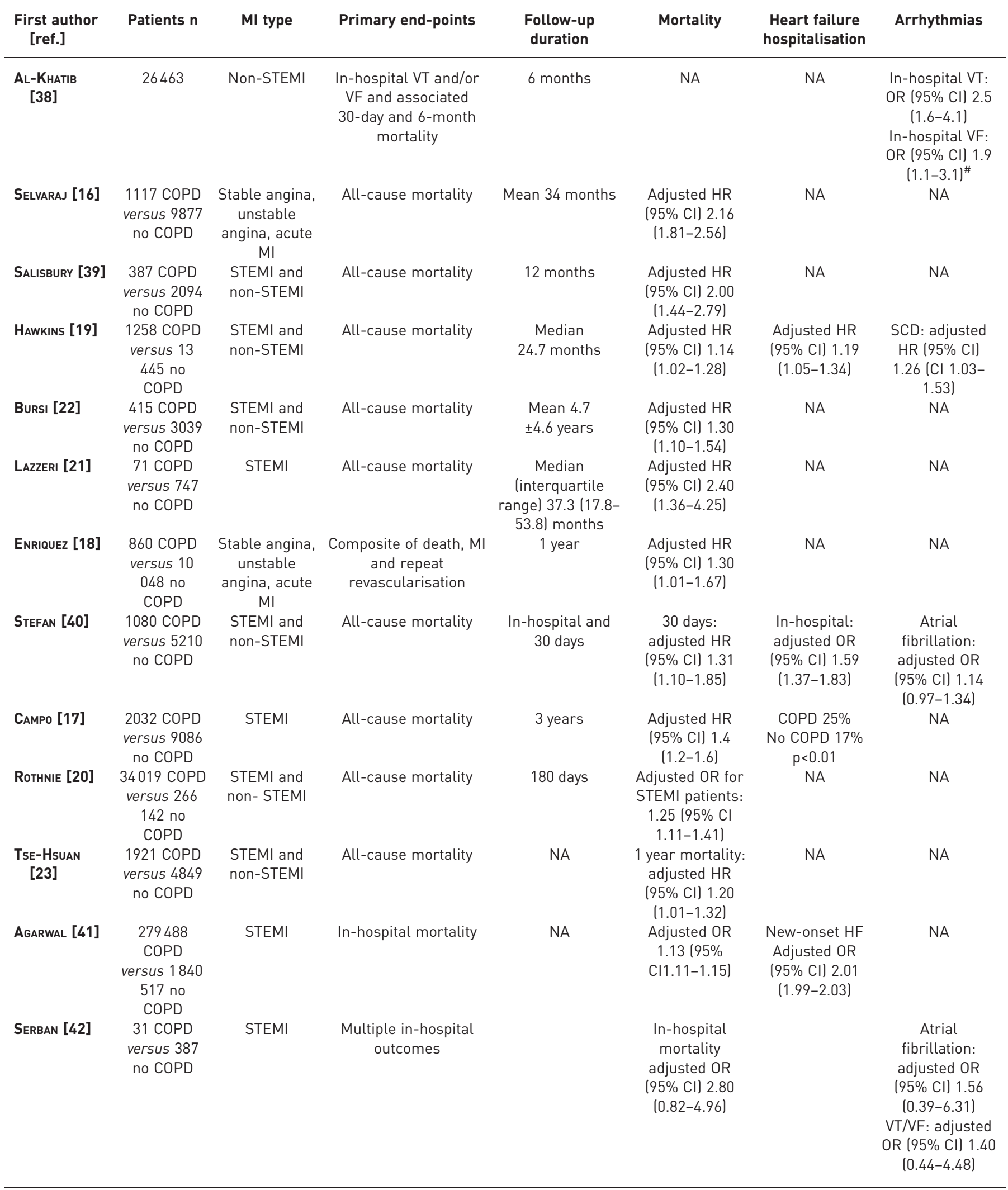

MI: myocardial infarction; STEMI: ST-segment elevation myocardial infarction; VT: ventricular tachycardia; VF: ventricular fibrillation; NA: not applicable; HF: heart failure; SCD: sudden cardiac death. \#: OR representing the presence of COPD as an independent predictor for the occurrence of in-hospital VT or VF. 


\section{Arrhythmias}

Cardiac arrhythmias, both supraventricular and ventricular, are common in patients with COPD [3, 43]. Data on the risk of arrhythmias after AMI associated with COPD are scarce. A meta-analysis of four randomised clinical trials, including 26436 non-STEMI patients and a history of COPD showed that COPD was an independent predictor of in-hospital ventricular arrhythmias (OR (95\% CI) 2.5 (1.6-4.1) and 1.9 (1.1-3.1) for ventricular tachycardia and ventricular fibrillation, respectively) [38]. Similarly, subanalysis of the VALIANT trial reported an increased risk of sudden cardiac death (SCD) during follow-up after AMI (STEMI and non-STEMI) for COPD patients compared to patients without COPD (HR (95\% CI) $1.26(1.03-1.53))$ [19].

In summary, the evidence on the detrimental impact of COPD on the outcome of patients experiencing AMI is accumulating. Although the exact pathophysiologic mechanisms are still largely unexplained, the need for adequate risk stratification to identify patients at risk for adverse events has been recognised as unmet clinical need. The following sections will focus on early recognition and treatment of patients with $\mathrm{AMI}$ and concomitant COPD and the role of imaging in the risk stratification.

\section{Unmet clinical needs in diagnosis and treatment of COPD patients with AMI Early detection}

Part of the differences in outcome between COPD and non-COPD patients could be explained by the diversity in clinical presentation, delaying diagnosis of AMI and leading to greater infarct size. Difficulties in recognising AMI in patients with COPD have been acknowledged in previous studies. Patients with COPD more often present with atypical chest pain or dyspnoea at the emergency room. In a large population of consecutive patients with AMI admitted to coronary care units in Sweden, 1092 (22.5\%) out of 4867 COPD patients presented with dyspnoea as opposed to 5429 (7.1\%) out of 76324 non-COPD patients [44]. A similar rate of COPD patients presenting with dyspnoea was observed by HADI et al. [45] and in a retrospective study performed by STEFAN et al. [40] $>60 \%$ of COPD patients with AMI presented with dyspnoea. Furthermore, COPD patients more often present with non-STEMI or unstable angina instead of STEMI as compared to non-COPD patients, increasing the risk of misdiagnosis and delayed intervention $[19,39,40,44,46]$.

\section{Controversy in treatment}

A possible consequence of misleading symptoms in COPD patients with AMI is delayed reperfusion and subsequent greater infarct size and/or worse prognosis. This was demonstrated by RoTHNIE et al. [21] with a median of $43.7 \mathrm{~min}$ longer to reperfusion among COPD patients compared to non-COPD patients, both with delayed diagnosis of AMI. After adjustment for several factors, the difference in time to reperfusion remained $47 \%$ longer for COPD patients with delayed diagnosis of AMI compared to their counterparts (95\% CI 15-88\%). In contrast, a large Swedish study including 81191 patients with AMI showed that COPD patients were less likely to arrive at the coronary care unit within $12 \mathrm{~h}$ after symptom onset $(84 \%$ versus $87.4 \%$; $\mathrm{p}<0.001$ ) compared to non-COPD patients but still the rate of patients with percutaneous coronary intervention within $12 \mathrm{~h}$ after symptom onset was similar for both groups of patients $(91.1 \%$ versus $91.9 \%, \mathrm{p}=0.488$ ) [44]. This was confirmed in a smaller STEMI population comparing 71 COPD patients with 747 non-COPD patients, demonstrating similar door-to-balloon time in the two groups (median (IQR) 180 (140-360) min versus 230 (160-303) min; $\mathrm{p}=0.314$, for COPD and non-COPD patients, respectively) [21]. Therefore, convincing evidence for delayed intervention in COPD patients compared to patients without COPD is lacking, although comparison of the above-mentioned studies should be performed with caution due to differences in study populations.

While controversy in literature exists with regard to delayed reperfusion treatment in COPD patients compared to patients without COPD, recent studies recognise lower rates of immediate intervention in AMI patients with COPD. At the moment of presentation, patients with COPD are less likely to receive diagnostic angiography or percutaneous coronary intervention compared to patients without COPD [20, 22, 41, 44]. The factors related to the hesitation for invasive diagnostics and/or treatment in COPD patients presenting with AMI have not been elucidated. A possible explanation is that COPD patients are deemed to be older with higher frailty, which could lead to hesitation for aggressive treatment.

Besides invasive treatment strategies, controversy exists on pharmacological treatment after AMI in patients with COPD. In particular, the use of $\beta$-blockers has been a subject of debate in many studies and clinical practice. Evidence is accumulating in favour of the use of $\beta$-blockers in patients with COPD in terms of safety and mortality reduction, but clinicians still seem to be reluctant to prescribe these drugs in this particular population due to the fear of bronchoconstriction or pulmonary function decline. For example, a study considering 1573 high-risk AMI survivors with concomitant COPD evaluated the influence of $\beta$-blocker use on long-term survival [47]. Their results demonstrate that $\beta$-blocker use was 
associated with better outcome in terms of all-cause and cardiovascular mortality (HR (95\% CI) $0.73(0.60$ $0.90), \mathrm{p}=0.003$ and $0.77(0.61-0.97), \mathrm{p}=0.025$, respectively) [47]. Similar results were demonstrated in a previous population study by QUINT et al. [48] including 1036 COPD patients with a first AMI. Although only $38 \%$ of the patients were prescribed a $\beta$-blocker, after a median follow-up of 2.9 years there was a clear survival benefit for patients using a $\beta$-blocker initiated at admission for AMI compared to patients in whom $\beta$-blockers were not prescribed (HR (5\% CI) $0.50(0.36-0.69)$ ) [48]. Despite the evident survival benefit of using $\beta$-blockers in COPD patients after AMI, observational studies considering infarction populations report a $4 \%$ to $30 \%$ lower rate of $\beta$-blocker prescription at discharge in COPD patients compared to patients without COPD [17, 19-22, 39, 40,44,46]. As expected, this topic will continue to be a subject of debate both in COPD patients with ischaemic heart disease as well as heart failure.

\section{Guideline-based secondary prevention in AMI patients with COPD}

Besides $\beta$-blockers, there are several other medications of importance to preventing future cardiovascular events after AMI, such as anti-platelet, statins and angiotensin converting enzyme inhibitors or angiotensin II receptor blockers. Several reviews have been written about the management of cardiovascular risk or disease in COPD patients [49-51]. Although many studies regarding the effect of such medications concern COPD patients without overt cardiovascular disease, few registries, post-hoc analysis and observational studies are indicating to treat patients with cardiovascular disease and concomitant COPD no differently in terms of secondary cardiovascular prevention [50]. A brief summary of the available literature on this subject is presented in table 2.

\section{Risk stratification: role of cardiac imaging}

Since the risk of adverse events (e.g. reinfarction, heart failure or death) after AMI is most substantial shortly after the index event and decreases over time, early risk assessment is warranted [5]. Risk assessment after AMI commences with evaluation of infarct size and resting LV function before hospital discharge. In addition to biomarkers (i.e. cholesterol, troponin, creatine phosphokinase), several imaging techniques are currently available for risk stratification. For evaluation of LV function and infarct size, transthoracic echocardiography is the most suitable and readily available imaging technique. Repeated evaluation of LV ejection fraction (LVEF) is appropriate for selection of patients requiring implantation of an internal cardioverter-defibrillator for primary prevention. Recently, novel imaging techniques such as speckle tracking echocardiography have emerged for assessment of atrial and ventricular deformation (strain imaging) and electrical conduction heterogeneity (mechanical dispersion). The following sections

\section{TABLE 2 Secondary prevention in COPD patients with cardiovascular disease}

\begin{tabular}{|c|c|c|c|}
\hline $\begin{array}{l}\text { First author } \\
\text { [ref.] }\end{array}$ & Patients n & $\begin{array}{l}\text { Medication } \\
\text { studied }\end{array}$ & Main results \\
\hline MANCINI [52] & $\begin{array}{l}\text { High-risk cohort of patients after } \\
\text { coronary revascularisation: } \\
946 \text { COPD patients using studied } \\
\text { medication } \\
18774 \text { COPD patients not using } \\
\text { studied medication }\end{array}$ & $\begin{array}{l}\text { Statins } \\
\text { ACE inhibitors } \\
\text { ARBs }\end{array}$ & $\begin{array}{l}\text { ARBs reduce risk of: } \\
\text { Death: RR } 0.62(95 \% \mathrm{Cl} 0.44-0.87) \\
\text { MI or death: } \mathrm{RR} 0.71(95 \% \mathrm{Cl} 0.56-0.89) \\
\text { Statins reduce risk of: } \\
\text { COPD hospitalisation RR } 0.71(95 \% \mathrm{Cl} 0.56-0.90) \\
\text { MI: RR } 0.48(95 \% \mathrm{Cl} 0.39-0.59) \\
\text { Death: RR } 053(95 \% \mathrm{Cl} 0.43-0.65) \\
\text { MI or death: RR } 0.50(95 \% \mathrm{Cl} 0.43-0.58) \\
\text { ACE inhibitors reduce risk of: } \\
\text { MI: RR } 0.72(95 \% \mathrm{Cl} 0.59-0.87) \\
\text { MI or death: } \mathrm{RR} 0.75(95 \% \mathrm{Cl} 0.64-0.86)\end{array}$ \\
\hline Sheng [53] & $\begin{array}{l}\text { COPD patients with established } \\
\text { cardiovascular disease: } \\
292 \text { with statin use } \\
151 \text { without statin use }\end{array}$ & Statins & $\begin{array}{l}\text { Recurrent CV event: adjusted HR } 0.35(95 \% \mathrm{Cl} 0.15-0.87) \\
\text { CV mortality: adjusted HR } 0.32(95 \% \mathrm{Cl} 0.13-0.77)\end{array}$ \\
\hline ANDELL [46] & $\begin{array}{l}1085 \text { COPD } \\
17528 \text { no COPD }\end{array}$ & $\begin{array}{l}\text { Ticagrelor versus } \\
\text { clopidogrel }\end{array}$ & $\begin{array}{l}\text { 1. Composite CV end-point: ticagrelor versus clopidogrel HR } 0.72 \\
(95 \% \mathrm{Cl} 0.54-0.97) \text { for COPD patients } \\
\text { 2. Relative risk for ticagrelor-related dyspnoea } 1.71(95 \% \mathrm{Cl} \\
1.28-2.30 \text { ) in COPD and } 1.85(95 \% \mathrm{Cl} 1.68-2.04) \text { in non-COPD } \\
\text { patients ( } \mathrm{p} \text { for interaction } 0.616)\end{array}$ \\
\hline
\end{tabular}

ACE: angiotensin converting enzyme; ARB: angiotensin II receptor blocker; MI: myocardial infarction; CV: cardiovascular. 
will discuss evaluation of: 1) LV size and function; 2) right ventricular (RV) systolic function; and 3) novel imaging techniques emerging for risk stratification after AMI, focusing on patients with concomitant COPD.

\section{LV size and function}

Assessment of LV function by using LVEF has a class I recommendation in STEMI guidelines [5]. LVEF predicts early all-cause mortality and SCD after AMI and has a role in therapeutic management. Besides LVEF, wall motion score index (WMSI) is a frequently used measure of systolic function after AMI [54]. For assessment of LV size and function, echocardiography remains the most widely used technique, due to its availability, lack of radiation exposure and relatively low cost. However, cardiac MRI is still considered the gold standard [55]. The advantage of cardiac MRI over echocardiography is its low inter- and intra-observer variability. Another disadvantage of echocardiography are the poor acoustic windows in patients with obesity and/or COPD. Despite the advantages of cardiac MRI, the limited availability, high costs and time-consuming examination and post-processing still lead to the preference of echocardiography in the setting of AMI. This is also stated in the most recent STEMI guidelines with a class IIb recommendation for CMR as an alternative to echocardiography [5].

As for patients with COPD, limited imaging studies have been performed in subpopulations with AMI. Conflicting results are described as to whether or not COPD patients have worse LVEF after STEMI, compared to patients without COPD [17-19, 21, 24, 39]. A retrospective cohort comparing 133 STEMI patients with COPD to 1617 STEMI patients without COPD demonstrated similar infarct size using conventional parameters such as LVEF and WMSI [24]. However, advanced echocardiographic parameters indicated greater infarct size in COPD patients (figure 2) [24]. In another large STEMI registry including 11118 patients of whom 2032 had a history of COPD, the percentage of patients with LVEF $<35 \%$ was significantly higher amongst COPD patients compared to their counterparts $(15 \%$ versus $12 \%(\mathrm{p}<0.01)$, respectively,). This is of particular interest since LVEF $\leqslant 35 \%$ is the main indication for internal cardioverter-defibrillator implantation [56]. Furthermore, in a substudy of the VALIANT trial including patients with AMI complicated with heart failure and/or LV dysfunction, the impact of COPD on clinical outcome was investigated [24]. Although similar LVEF values were observed in COPD patients compared to non-COPD patients ( $34 \%$ versus $35.4 \%$ ( $p>0.05)$, respectively,), the risk of SCD was significantly higher in COPD patients (adjusted HR (95\% CI) $1.26(1.03-1.53), \mathrm{p}=0.025)$ [19]. This stresses the need for better characterisation of the substrate for SCD in these patients.

Only a few cardiac MRI studies have been performed in patients with COPD, mainly focusing on patients without overt cardiovascular disease and mostly assessing the right side of the heart. Furthermore, cardiac MRI studies in AMI patients rarely mention the presence of COPD as a comorbidity in their patient populations and/or have small numbers [57]. This leaves a gap in knowledge on scar characterisation in patients with COPD.

Few studies have described smaller LV size in COPD patients without overt cardiovascular disease without impairment of LV function [58, 59]. Whether LV remodelling post-infarction is different in COPD patients compared to patients without COPD, has not been described before. This could be of interest to further elucidate the mortality risk and heart failure development in COPD patients after AMI.

\section{RV systolic function}

RV involvement in AMI has long been neglected and overshadowed by the importance of LV dysfunction. The awareness of the influence of RV systolic dysfunction on clinical status and prognosis after AMI has increased in the past decade. RV involvement is predominantly present in inferior AMI caused by proximal right coronary artery occlusion with a prevalence up to $30 \%$ depending on the diagnostic parameter used $[60,61]$. Previous studies have recognised the prognostic implications of RV dysfunction after AMI both in patients with inferior and anterior myocardial infarction $[60,62,63]$.

Assessment of RV systolic function is challenging due to complex RV geometry. In patients with AMI, cardiac MRI and echocardiography have contributed significantly to the understanding and evaluation of RV involvement. Although cardiac MRI remains the gold standard for RV systolic function assessment, various echocardiographic parameters are currently available to assess RV function in a bedside manner (figure 3). TAPSE, fractional area change and novel techniques such as RV strain are of important prognostic value in AMI, independently of LV function [62].

Although the RV is less vulnerable to ischaemia than the LV due to a more balanced oxygen supply and demand, this might be affected when RV hypertrophy or pulmonary hypertension is present [64]. In the normal situation, the thin-walled RV only has to perform little effort to create stroke volume into the low-resistance pulmonary vascular circulation. This changes when pulmonary hypertension is present, 


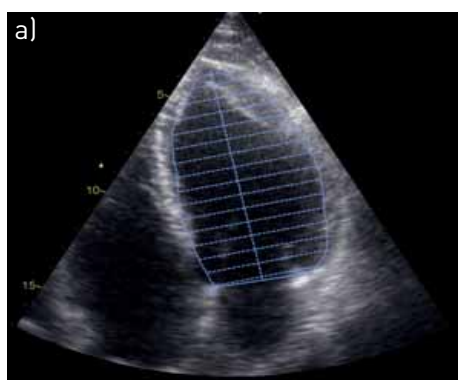

b)
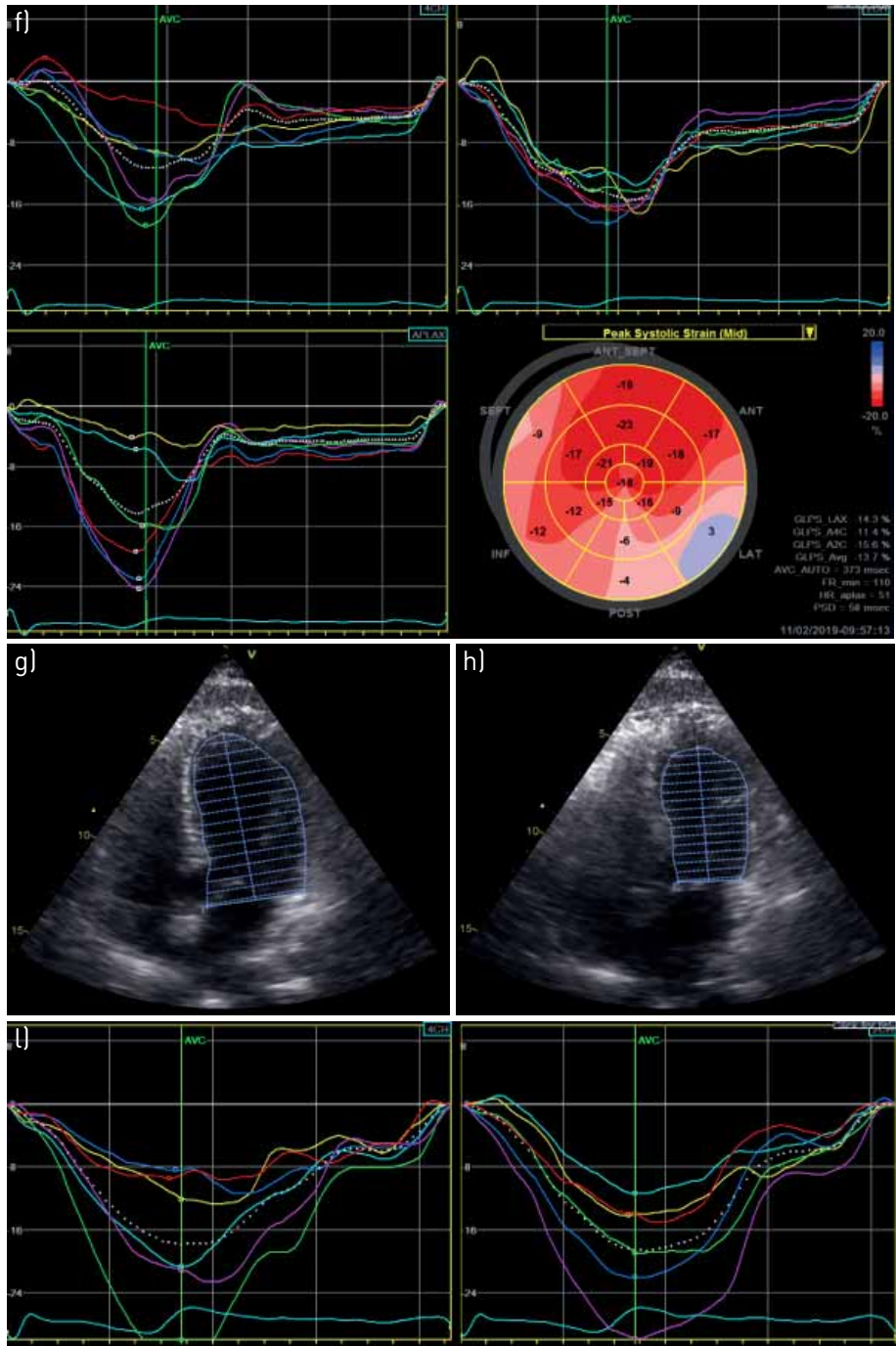

d)
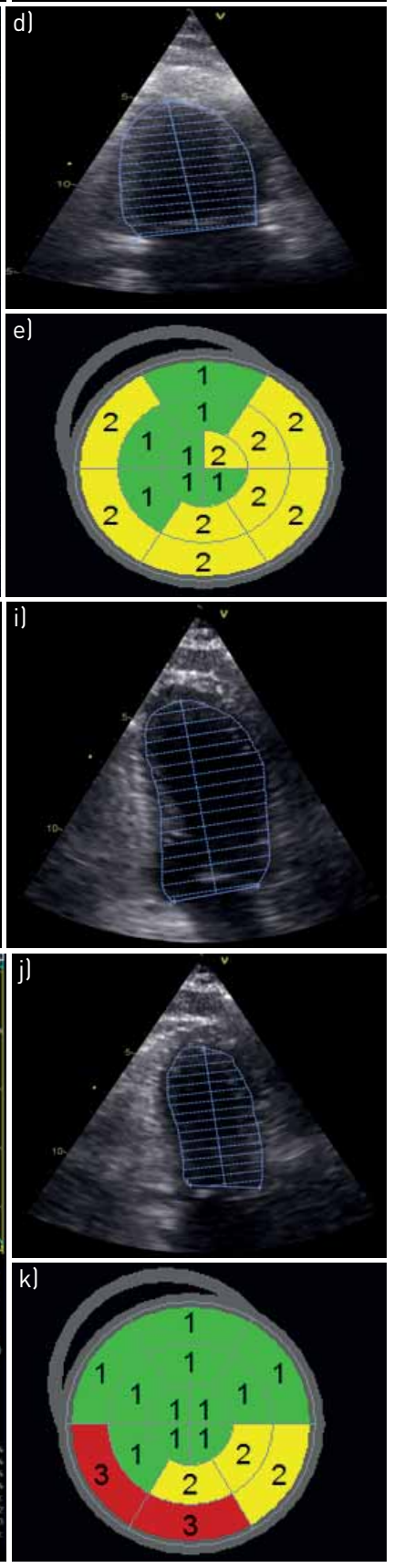

FIGURE 2 Left ventricular volume and function assessment with echocardiography. Example of two patients after ST-segment elevation myocardial infarction a-f) with COPD and $g-($ ) without COPD. Both patients had the circumflex artery as culprit vessel and similar cardiac biomarkers. Left ventricular ejection fraction (LVEF), assessed with biplane Simpson's method (a-d, $g-j$ ), was comparable in the two patients $145 \%$ versus $53 \%$, respectively). Wall motion score index $(e, k)$ was slightly higher in the COPD patient (1.56 versus 1.43 , respectively). Left ventricular longitudinal strain was strikingly more impaired (less negative) in the COPD patient ( $f$ ) compared to the patient without COPD (I) ( $-13.7 \%$ versus $-17.3 \%$, respectively). 

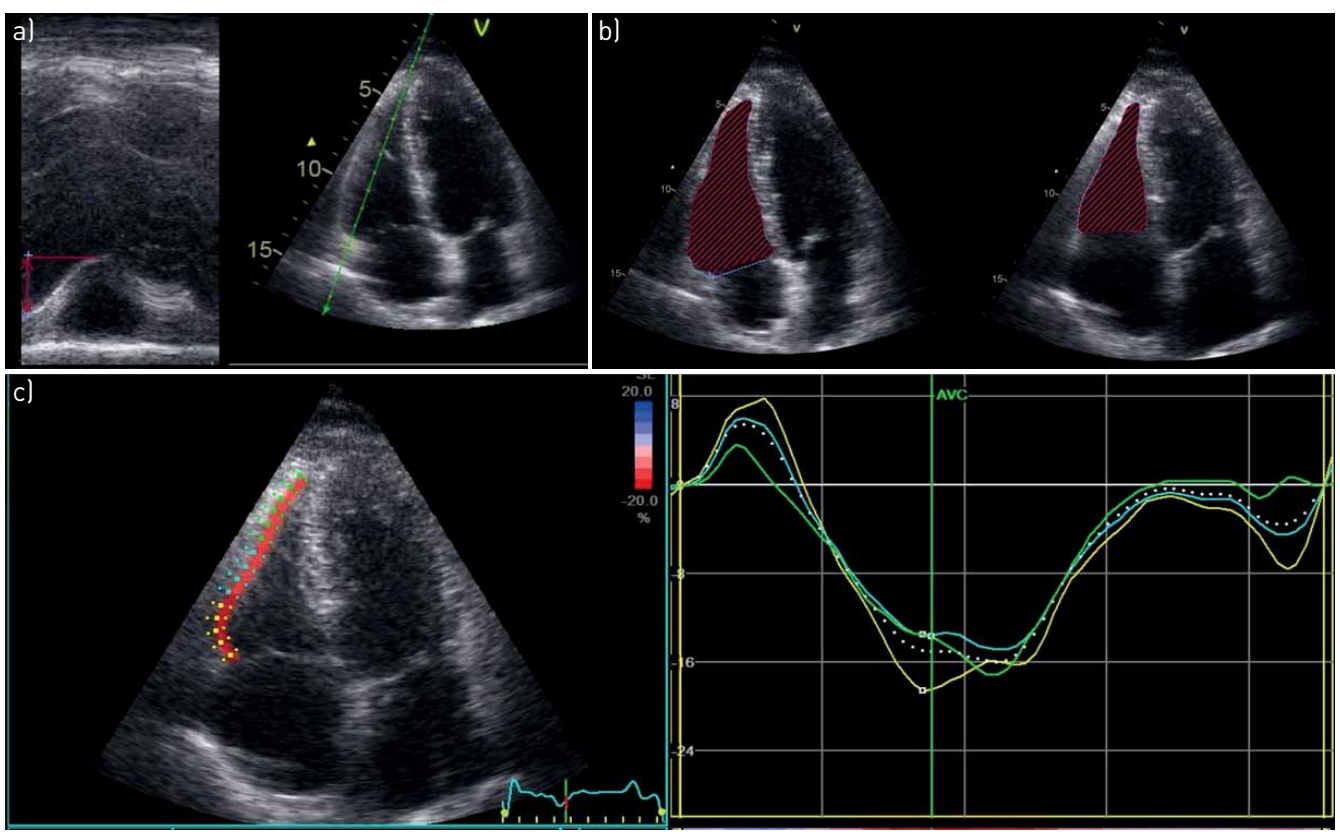

FIGURE 3 Right ventricular (RV) systolic function assessment in a ST-segment elevation myocardial infarction patient with COPD. Example of a patient with normal RV systolic function when assessed with conventional parameters such as a) tricuspid annular plane systolic excursion or b) fractional area change, but impaired RV systolic function when assessed with c) advanced speckle-tracking echocardiography.

leading to an increase in the oxygen demand of the RV and changes in the coronary flow, which then makes the RV more susceptible for ischaemia [64-66]. In patients with COPD, RV hypertrophy has shown to be present even in the absence of pulmonary hypertension. In a cardiac MRI study assessing 25 patients with COPD without evidence of pulmonary hypertension, RV mass was significantly higher compared to 26 healthy controls $(68 \pm 12 \mathrm{~g}$ versus $59 \pm 14 \mathrm{~g}$; $\mathrm{p}<0.01)$ [67]. This was also found in a study by SABIT et al. [68] using echocardiography to assess LV and RV structure and function in 36 COPD patients free of overt cardiovascular disease, compared to 14 current or ex-smokers. Particularly, greater RV free wall thickness and impaired RV systolic function based on tricuspid annular peak systolic velocity, RV strain and Tei index were demonstrated in COPD patients [68]. These differences were observed in both patients with mild airflow obstruction and more diseased patients with evidence of pulmonary hypertension. These studies indicate the presence of RV remodelling and subclinical dysfunction in early stages of COPD, before overt cardiac disease.

Studies concerning the assessment of RV systolic function after AMI in patients with COPD are lacking. In addition, although the general population frequently show RV functional recovery after AMI, this remains unknown among COPD patients who might already have subclinical damage [69]. Therefore, future research on this subject is required in order to elucidate the influence of COPD on RV function after AMI and the subsequent prognostic implications.

Cardiac MRI is considered the reference standard for the measurement of RV volumes and function but the availability is limited, especially in the acute setting. Echocardiography is a more available imaging technique and nowadays various parameters are available for assessment of RV systolic function. However, the complex geometry of the RV makes assessment of RV dimensions and function with echocardiography more challenging compared to the LV.

\section{Novel imaging markers for risk stratification \\ Speckle-tracking echocardiography}

Besides conventional echocardiography, LV function can be assessed using speckle-tracking echocardiography (figure 4a). This enables measurement of active deformation (strain) of the myocardium, either longitudinal, circumferential or radial. Global longitudinal strain (GLS) has been thought to indirectly represent myocardial fibrosis or scar, and has been associated with prognosis in various cardiac diseases. In STEMI patients, GLS has been independently associated with increased all-cause mortality, cardiovascular mortality, heart failure, SCD and appropriate internal cardioverter-defibrillator therapy $[7,8,74]$. Interestingly, in a retrospective study including 143 STEMI patients with COPD, GLS was independently 

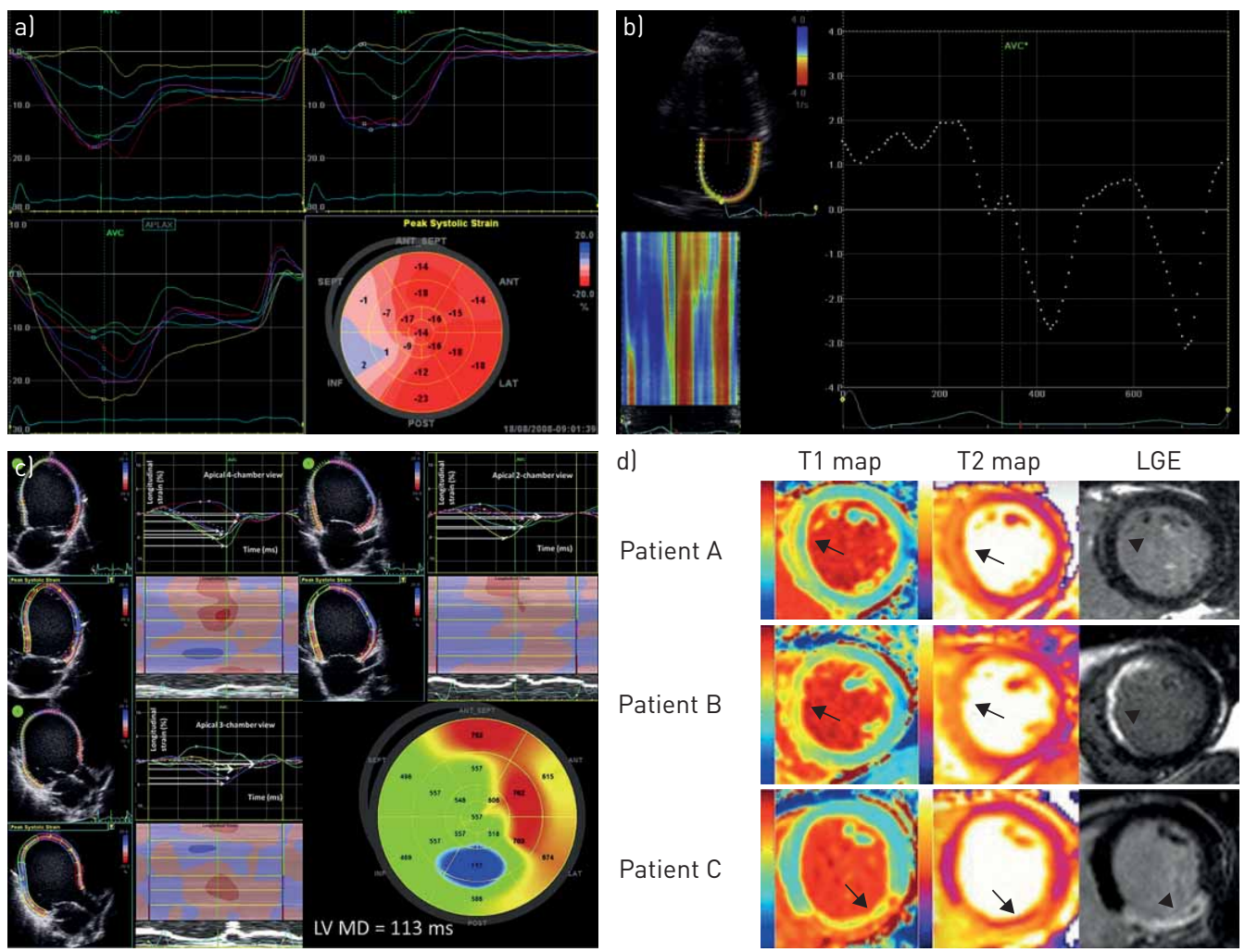

FIGURE 4 Examples of novel imaging techniques for risk assessment. With speckle tracking echocardiography a) left ventricular (LV) global longitudinal strain (GLS), b) left atrial strain and c) mechanical dispersion can be assessed. al Impaired LV GLS in a patient with ST-segment elevation myocardial infarction (STEMI) is demonstrated in the infarcted area (blue and pink segments) as opposed to normal values in the noninfarcted area (red segments). b) Example of a STEMI patient with impaired atrial strain. c) Increased LV mechanical dispersion (red segments) in heart failure patients with cardiac resynchronisation therapy can predict all-cause mortality and ventricular arrhythmias. d) T1 mapping performs as well as T2 mapping in quantifying the area at risk (arrows) after reperfusion in STEMI patients with varying degrees of myocardial salvage (assessed with late gadolinium enhancement) (arrowheads). Reproduced from a) [70], b) [71], c) [72] and d) [73], with permission from the publisher.

associated with all-cause mortality and a combined end-point including all-cause mortality and heart failure admission [75]. In addition, GLS had incremental value over conventional LVEF and TAPSE [75]. Therefore, GLS might serve as a better marker for risk stratification after STEMI in patients with COPD as opposed to conventional measures for LV and RV function. Myocardial strain assessment can also be performed by cardiac MRI, using several techniques. However, convincing evidence on the prognostic value of cardiac MRI-derived myocardial strain after STEMI is lacking due to limited studies with small populations and conflicting results [76].

In addition to GLS, speckle-tracking echocardiography can be used to assess the time to peak longitudinal strain in each of the $17 \mathrm{LV}$ segments. The standard deviation of these 17 segments, so-called mechanical dispersion, represents the heterogeneity of electrical conduction in the myocardium (figure 4c). Increased LV mechanical dispersion has been associated with increased risk of SCD and/or ventricular arrhythmias in patients after STEMI, heart failure patients receiving cardiac resynchronisation therapy but also in hypertrophic cardiomyopathy patients where mechanical dispersion was also associated with myocardial fibrosis [72, 74, 77]. The Rotterdam study, a population-based cohort study among 14926 participants, demonstrated a $>30 \%$ increased risk of SCD in patients with COPD, especially in those with frequent exacerbations [78]. Additionally, another study indicated an increased risk of ventricular arrhythmias in patients with COPD, irrespective of LVEF [79]. However, the pathophysiology behind this pro-arrhythmogenicity has not been completely elucidated, and assessment of mechanical dispersion could be of additional value.

Atrial mechanics

The importance of left atrial volume and function as markers of adverse events after AMI has emerged in the past decade $[80,81]$. Left atrial volume is considered to represent LV diastolic function and increased 

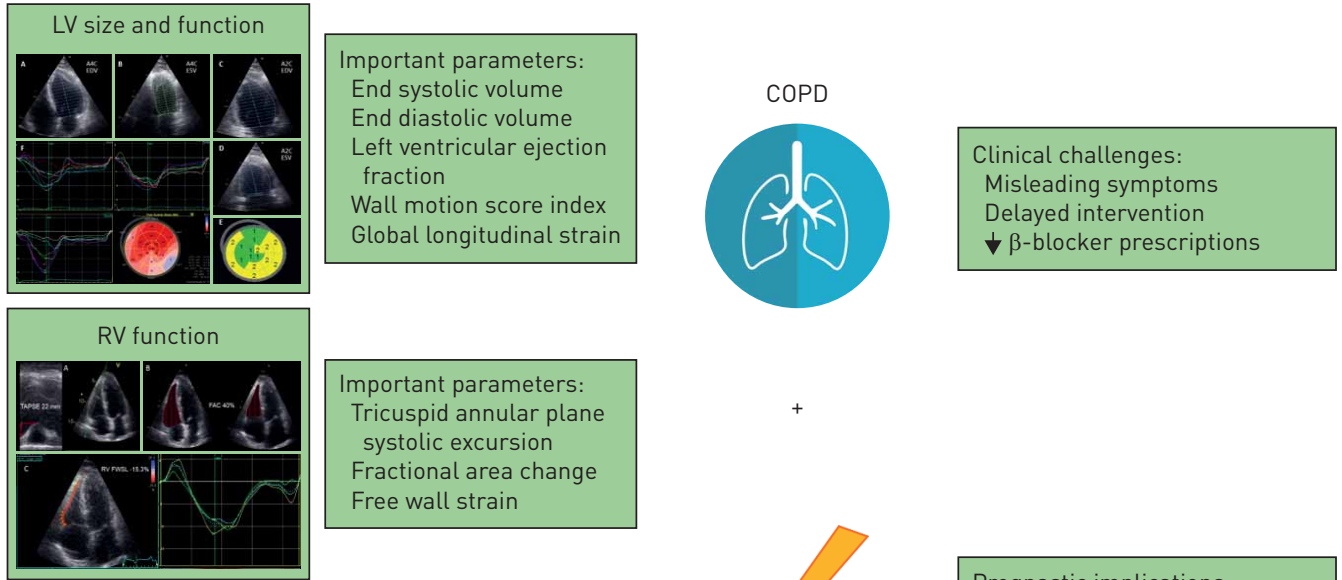

Novel imaging techniques
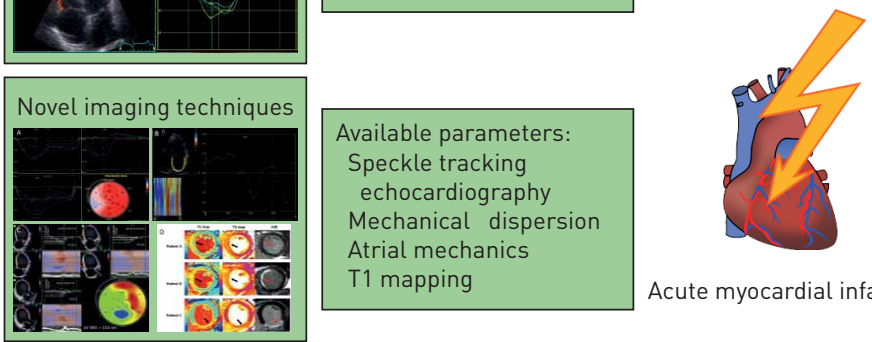

Prognastic implications:

4 Mortality

4 Heart failure hospitalisations

4 Ventricular arrhythmias

FIGURE 5 The role of imaging in risk stratification after acute myocardial infarction in patients with COPD. Diagnosis of acute myocardial infarction in patients with COPD can be challenging due to misleading symptoms leading to delayed intervention. Increased rates of mortality, heart failure hospitalisations and ventricular arrhythmias have been described. Cardiac imaging has an important role in risk stratification after acute myocardial infarction. In patients with COPD after acute myocardial infarction, different imaging modalities and parameters can be used to assess left ventricular (LV) size and function and right ventricular (RV) function to aid risk stratification. Novel imaging techniques could further help to identify patients at risk for adverse events during follow-up. Insert images taken from figure 4 and reproduced with permission as previously stated [70-73] with permission from the publisher.

left atrial volume can arise from chronic increased LV filling pressures. An AMI can result in (worsening of) diastolic dysfunction and subsequent left atrial remodelling. The evidence suggests that this process starts early after AMI and can deteriorate over time, leading to worse prognosis [80, 81]. Diastolic dysfunction frequently occurs in patients with COPD, partly due to hyperinflation leading to impaired LV filling [82]. Therefore, left atrial volume overload might be unlikely in COPD patients. However, the chronic systemic inflammatory status and frequently occurring pulmonary hypertension might lead to atrial remodelling, resulting in decreased atrial function [39].

Besides left atrial volume, determination of left atrial function has proven to be of additional value in predicting adverse events after AMI [83]. Analysis of left atrial function can be performed using conventional echocardiography, as well as speckle tracking (figure $4 \mathrm{~b}$ ). Atrial function can be divided into the reservoir phase (during ventricular systole), conduit phase (passive emptying during ventricular relaxation) and the contractile phase (active emptying) [83]. In a retrospective study concerning 320 AMI patients, left atrial reservoir strain was independently associated with a composite of all-cause mortality, reinfarction and hospitalisation for heart failure (HR (95\% CI) 0.94 (0.89-0.99), p=0.02). More recently, NOURIAN et al. [84] measured right atrial strain in 70 patients with inferior myocardial infarction. Right atrial reservoir and conduit functions were impaired in patients with RV infarction compared to patients without RV infarction [84]. Whether right atrial strain has prognostic implications has not been investigated.

Speckle-tracking echocardiography allows evaluation of the active deformation of the myocardium in multiple directions which is less angle and volume dependent in comparison with measurements used in conventional echocardiography. A disadvantage of this technique is the inter-vendor differences originating from different software algorithms, limiting comparison of results obtained across the studies.

\section{T1 mapping}

Cardiac MRI imaging with late gadolinium enhancement is considered the gold standard for measurement of infarct size after AMI; however, post-contrast T1 mapping has recently emerged as a new cardiac MRI technique. Few studies have demonstrated that native T1 mapping can accurately quantify infarct size and the oedema-based area at risk when compared to conventional T2 mapping and late gadolinium enhancement imaging (fig. 4d) [73, 85]. Also, T1 mapping has been identified as a strong predictor of LV 
remodelling post-infarction [85]. This promising technique could potentially shorten scanning time substantially, making cardiac MRI a more suitable imaging technique in STEMI patients. Interestingly, a pilot cardiac MRI study was performed in patients with COPD, free of overt cardiovascular disease, using T1 mapping to assess myocardial extracellular volume (ECV) as a measure of cardiac fibrosis [86]. In the eight COPD patients, an increased ECV was observed compared to healthy controls (median 0.32 versus $0.27, \mathrm{p}=0.001$ ). This was associated with LV remodelling, reduced left atrial function and reduced exercise capacity [86]. Although this was a small pilot study, the results indicate the feasibility of T1 mapping in COPD patients to detect signs of cardiac fibrosis related to clinical status.

The benefit of T1 mapping over conventional T2 mapping and late gadolinium enhancement imaging could be a significant shortening in acquisition time which is particularly valuable in AMI patients. However, T1 mapping has only been tested in a few small studies concerning patients with first AMI and the value of $\mathrm{T} 1$ mapping in patients with previous myocardial infarction has to be determined.

In summary, echocardiography remains the most widely used imaging technique for risk stratification after AMI. Advanced echocardiographic parameters have already provided new insights in the prognosis of AMI patients, but further research is still needed. Although imaging studies in AMI patients with concomitant COPD are scarce, studies evaluating cardiac function in COPD patients indicate the presence of cardiac dysfunction even before the first cardiovascular event. This emphasises the need for further research to better understand the consequence of myocardial infarction further damaging an already injured heart.

\section{Conclusion}

Patients with COPD carry an increased risk of AMI through various pathophysiological pathways. Following AMI, the rate of adverse events is higher in COPD patients when compared to patients without COPD, which might in part be due to a delay in recognition and subsequent revascularisation. Echocardiography has already shown that COPD patients might be more vulnerable to ischaemia, leading to worse cardiac function when compared to patients without COPD. Advanced imaging techniques could play a pivotal role in risk stratification after AMI in patients with (and without) COPD (figure 5).

Conflict of interest: L. Goedemans has nothing to disclose. J.J. Bax reports grants from Medtronic, Boston scientific, Edwards Lifesciences and Biotronik, outside the submitted work. V. Delgado reports personal fees from Abbott Vascular, and grants from Medtronic, Boston scientific, Edwards Lifesciences and Biotronik, outside the submitted work.

\section{References}

1 Celli BR, Wedzicha JA. Update on clinical aspects of chronic obstructive pulmonary disease. N Eng J Med 2019; 381: $1257-1266$

2 Vogelmeier CF, Criner GJ, Martinez FJ, et al. Global strategy for the diagnosis, management, and prevention of chronic obstructive lung disease 2017 report. GOLD executive summary. Am J Respir Crit Care Med 2017; 195: 557-582.

3 Lopez-Campos JL, Tan W, Soriano JB. Global burden of COPD. Respirology 2016; 21: 14-23.

4 Chen W, Thomas J, Sadatsafavi M, et al. Risk of cardiovascular comorbidity in patients with chronic obstructive pulmonary disease: a systematic review and meta-analysis. Lancet Respir Med 2015; 3: 631-639.

5 McGarvey LP, John M, Anderson JA, et al. Ascertainment of cause-specific mortality in COPD: operations of the TORCH Clinical Endpoint Committee. Thorax 2007; 62: 411-415.

6 Steg PG, James SK, Atar D, et al. ESC Guidelines for the management of acute myocardial infarction in patients presenting with ST-segment elevation. Eur Heart J 2012; 33: 2569-2619.

7 O'Gara PT, Kushner FG, Ascheim DD, et al. 2013 ACCF/AHA guideline for the management of ST-elevation myocardial infarction: a report of the American College of Cardiology Foundation/American Heart Association Task Force on practice guidelines. J Am Coll Cardiol 2013; 61: e78-e140.

8 Antoni ML, Mollema SA, Delgado V, et al. Prognostic importance of strain and strain rate after acute myocardial infarction. Eur Heart J 2010; 31: 1640-1647.

9 Ersboll M, Valeur N, Mogensen UM, et al. Prediction of all-cause mortality and heart failure admissions from global left ventricular longitudinal strain in patients with acute myocardial infarction and preserved left ventricular ejection fraction. J Am Coll Cardiol 2013; 61: 2365-2373.

10 Wong DTL, Richardson JD, Puri R, et al. The role of cardiac magnetic resonance imaging following acute myocardial infarction. Eur Radiol 2012; 22: 1757-1768.

11 Mannino DM, Thorn D, Swensen A, et al. Prevalence and outcomes of diabetes, hypertension and cardiovascular disease in COPD. Eur Respir J 2008; 32: 962.

12 Sin DD. Why are patients with chronic obstructive pulmonary disease at increased risk of cardiovascular diseases? The potential role of systemic inflammation in chronic obstructive pulmonary disease. Circulation 2003; 107: 1514-1519.

13 Wedzicha JA, Seemungal TA, MacCallum PK, et al. Acute exacerbations of chronic obstructive pulmonary disease are accompanied by elevations of plasma fibrinogen and serum IL-6 levels. Thromb Haemost 2000; 84: 210-215.

14 Ashitani J, Mukae H, Arimura Y, et al. Elevated plasma procoagulant and fibrinolytic markers in patients with chronic obstructive pulmonary disease. Intern Med 2002; 41: 181-185. 
15 MacNee W. Systemic inflammatory biomarkers and co-morbidities of chronic obstructive pulmonary disease. Ann Med 2013; 45: 291-300.

16 Phatharajaree W, Phrommintikul A, Chattipakorn N. Matrix metalloproteinases and myocardial infarction. Can J Cardiol 2007; 23: 727-733.

17 Selvaraj CL, Gurm HS, Gupta R, et al. Chronic obstructive pulmonary disease as a predictor of mortality in patients undergoing percutaneous coronary intervention. Am J Cardiol 2005; 96: 756-759.

18 Campo G, Guastaroba P, Marzocchi A, et al. Impact of COPD on long-term outcome after ST-segment elevation myocardial infarction receiving primary percutaneous coronary intervention. Chest 2013; 144: 750-757.

19 Enriquez JR, Parikh SV, Selzer F, et al. Increased adverse events after percutaneous coronary intervention in patients with COPD: insights from the National Heart, Lung, and Blood Institute dynamic registry. Chest 2011; 140: 604-610.

20 Hawkins NM, Huang Z, Pieper KS, et al. Chronic obstructive pulmonary disease is an independent predictor of death but not atherosclerotic events in patients with myocardial infarction: analysis of the Valsartan in Acute Myocardial Infarction Trial (VALIANT). Eur J Heart Fail 2009; 11: 292-298.

21 Rothnie KJ, Smeeth L, Herrett E, et al. Closing the mortality gap after a myocardial infarction in people with and without chronic obstructive pulmonary disease. Heart 2015; 101: 1103-1110.

22 Lazzeri C, Valente S, Attana P, et al. The prognostic role of chronic obstructive pulmonary disease in ST-elevation myocardial infarction after primary angioplasty. Eur J Prev Cardiol 2013; 20: 392-398.

23 Bursi F, Vassallo R, Weston SA, et al. Chronic obstructive pulmonary disease after myocardial infarction in the community. Am Heart J 2010; 160: 95-101.

24 Su TH, Chang SH, Chen PC, et al. Temporal trends in treatment and outcomes of acute myocardial infarction in patients with chronic obstructive pulmonary disease: a nationwide population-based observational study. $\mathrm{J} A m$ Heart Assoc 2017; 6: e004525.

25 Goedemans L, Abou R, Hoogslag GE, et al. Comparison of left ventricular function and myocardial infarct size determined by 2-dimensional speckle tracking echocardiography in patients with and without chronic obstructive pulmonary disease after ST-segment elevation myocardial infarction. Am J Cardiol 2017; 120: 734-739.

26 Almagro P, Lapuente A, Pareja J, et al. Underdiagnosis and prognosis of chronic obstructive pulmonary disease after percutaneous coronary intervention: a prospective study. Int J Chron Obstruct Pulmon Dis 2015; 10: 1353-1361.

27 Soriano JB, Rigo F, Guerrero D, et al. High prevalence of undiagnosed airflow limitation in patients with cardiovascular disease. Chest 2010; 137: 333-340.

28 Campo G, Pavasini R, Barbetta C, et al. Predischarge screening for chronic obstructive pulmonary disease in patients with acute coronary syndrome and smoking history. Int J Cardiol 2016; 222: 806-812.

29 Schneider C, Bothner U, Jick SS, et al. Chronic obstructive pulmonary disease and the risk of cardiovascular diseases. Eur J Epidemiol 2010; 25: 253-260.

30 Feary JR, Rodrigues LC, Smith CJ, et al. Prevalence of major comorbidities in subjects with COPD and incidence of myocardial infarction and stroke: a comprehensive analysis using data from primary care. Thorax 2010; 65: 956-962.

31 Thomsen M, Dahl M, Lange $\mathrm{P}$, et al. Inflammatory biomarkers and comorbidities in chronic obstructive pulmonary disease. Am J Respir Crit Care Med 2012; 186: 982-988.

32 Campo G, Pavasini R, Malagù M, et al. Relationship between troponin elevation, cardiovascular history and adverse events in patients with acute exacerbation of COPD. COPD 2015; 12: 560-567.

33 Høiseth AD, Neukamm A, Karlsson BD, et al. Elevated high-sensitivity cardiac troponin T is associated with increased mortality after acute exacerbation of chronic obstructive pulmonary disease. Thorax 2011; 66: 775-781.

34 Wang WQ, Huang HL, Zhu S, et al. High-sensitivity cardiac troponin T in patients with acute myocardial infarction in acute exacerbation of chronic obstructive pulmonary disease. Clin Lab 2015; 61: 1083-1093.

35 McAllister DA, Maclay JD, Mills NL, et al. Diagnosis of myocardial infarction following hospitalisation for exacerbation of COPD. Eur Respir J 2012; 39: 1097-1103.

36 Pizarro C, Herweg-Steffens N, Buchenroth M, et al. Invasive coronary angiography in patients with acute exacerbated COPD and elevated plasma troponin. Int J Chron Obstruct Pulmon Dis 2016; 11: 2081-2089.

37 Adamson PD, Anderson JA, Brook RD, et al. Cardiac troponin I and cardiovascular risk in patients with chronic obstructive pulmonary disease. J Am Coll Cardiol 2018; 72: 1126-1137.

38 Al-Khatib SM, Granger CB, Huang Y, et al. Sustained ventricular arrhythmias among patients with acute coronary syndromes with no ST-segment elevation: incidence, predictors, and outcomes. Circulation 2002; 106: 309-312.

39 Salisbury AC, Reid KJ, Spertus JA. Impact of chronic obstructive pulmonary disease on post-myocardial infarction outcomes. Am J Cardiol 2007; 99: 636-641.

40 Stefan MS, Bannuru RR, Lessard D, et al. The impact of COPD on management and outcomes of patients hospitalized with acute myocardial infarction: a 10-year retrospective observational study. Chest 2012; 141: $1441-1448$.

41 Agarwal M, Agrawal S, Garg L, et al. Effect of chronic obstructive pulmonary disease on in-hospital mortality and clinical outcomes after ST-Segment elevation myocardial infarction. Am J Cardiol 2017; 119: 1555-1559.

42 Serban RC, Hadadi L, Sus I, et al. Impact of chronic obstructive pulmonary disease on in-hospital morbidity and mortality in patients with ST-segment elevation myocardial infarction treated by primary percutaneous coronary intervention. Int J Cardiol 2017; 243: 437-442.

43 Goudis CA, Konstantinidis AK, Ntalas IV, et al. Electrocardiographic abnormalities and cardiac arrhythmias in chronic obstructive pulmonary disease. Int J Cardiol 2015; 199: 264-273.

44 Andell P, Koul S, Martinsson A, et al. Impact of chronic obstructive pulmonary disease on morbidity and mortality after myocardial infarction. Open Heart 2014; 1: e000002.

45 Hadi HA, Zubaid M, Al Mahmeed W, et al. Prevalence and prognosis of chronic obstructive pulmonary disease among 8167 Middle Eastern patients with acute coronary syndrome. Clin Cardiol 2010; 33: 228-235.

46 Andell P, James SK, Cannon CP, et al. Ticagrelor versus clopidogrel in patients with acute coronary syndromes and chronic obstructive pulmonary disease: an analysis from the Platelet Inhibition and Patient Outcomes (PLATO) trial. J Am Heart Assoc 2015; 4: e002490.

47 Coiro S, Girerd N, Rossignol P, et al. Association of beta-blocker treatment with mortality following myocardial infarction in patients with chronic obstructive pulmonary disease and heart failure or left ventricular dysfunction: 
a propensity matched-cohort analysis from the High-Risk Myocardial Infarction Database Initiative. Eur J Heart Fail 2017; 19: 271-279.

48 Quint JK, Herrett E, Bhaskaran K, et al. Effect of beta blockers on mortality after myocardial infarction in adults with COPD: population-based cohort study of UK electronic healthcare records. BMJ 2013; 347: f6650.

49 Roversi S, Fabbri LM, Sin DD, et al. Chronic obstructive pulmonary disease and cardiac diseases. An urgent need for integrated care. Am J Respir Crit Care Med 2016; 194: 1319-1336.

50 Vanfleteren LEGW, Spruit MA, Wouters EFM, et al. Management of chronic obstructive pulmonary disease beyond the lungs. Lancet Respir Med 2016; 4: 911-924.

51 Campo G, Pavasini R, Biscaglia S, et al. Overview of the pharmacological challenges facing physicians in the management of patients with concomitant cardiovascular disease and chronic obstructive pulmonary disease. Eur Heart J Cardiovasc Pharmacother 2015; 1: 205-211.

52 Mancini GB, Etminan M, Zhang B, et al. Reduction of morbidity and mortality by statins, angiotensin-converting enzyme inhibitors, and angiotensin receptor blockers in patients with chronic obstructive pulmonary disease. $J \mathrm{Am}$ Coll Cardiol 2006; 47: 2554-2560.

53 Sheng X, Murphy MJ, MacDonald TM, et al. Effect of statins on total cholesterol concentrations, cardiovascular morbidity, and all-cause mortality in chronic obstructive pulmonary disease: a population-based cohort study. Clin Ther 2012; 34: 374-384.

54 Baron T, Flachskampf FA, Johansson $\mathrm{K}$, et al. Usefulness of traditional echocardiographic parameters in assessment of left ventricular function in patients with normal ejection fraction early after acute myocardial infarction: results from a large consecutive cohort. Eur Heart J Cardiovasc Imaging 2016; 17: 413-420.

55 Collins JD. Global and regional functional assessment of ischemic heart disease with cardiac MR imaging. Radiol Clin North Am 2015; 53: 369-395.

56 Al-Khatib SM, Stevenson WG, Ackerman MJ, et al. 2017 AHA/ACC/HRS guideline for management of patients with ventricular arrhythmias and the prevention of sudden cardiac death. J Am Coll Cardiol 2018; 72: e91-e220.

57 Pontone G, Guaricci AI, Andreini D, et al. Prognostic stratification of patients with ST-segment-elevation myocardial infarction (PROSPECT): a cardiac magnetic resonance study. Circ Cardiovasc Imaging 2017; 10: e006428.

58 Pela G, Li Calzi M, Pinelli S, et al. Left ventricular structure and remodeling in patients with COPD. Int J Chron Obstruct Pulmon Dis 2016; 11: 1015-1022.

59 Watz H, Waschki B, Meyer T, et al. Decreasing cardiac chamber sizes and associated heart dysfunction in COPD: role of hyperinflation. Chest 2010; 138: 32-38.

60 Park SJ, Park JH, Lee HS, et al. Impaired RV global longitudinal strain is associated with poor long-term clinical outcomes in patients with acute inferior STEMI. JACC Cardiovasc Imaging 2015; 8: 161-169.

61 Gorter TM, Lexis CP, Hummel YM, et al. Right ventricular function after acute myocardial infarction treated with primary percutaneous coronary intervention (from the glycometabolic intervention as adjunct to primary percutaneous coronary intervention in ST-segment elevation myocardial infarction III trial). Am J Cardiol 2016; 118: $338-344$.

62 Antoni ML, Scherptong RW, Atary JZ, et al. Prognostic value of right ventricular function in patients after acute myocardial infarction treated with primary percutaneous coronary intervention. Circ Cardiovasc Imaging 2010; 3: 264-271.

63 Zornoff LA, Skali H, Pfeffer MA, et al. Right ventricular dysfunction and risk of heart failure and mortality after myocardial infarction. J Am Coll Cardiol 2002; 39: 1450-1455.

64 Crystal GJ, Pagel PS. Right ventricular perfusion: physiology and clinical implications. Anesthesiology 2018; 128 : 202-218.

65 Kopelman HA, Forman MB, Wilson BH, et al. Right ventricular myocardial infarction in patients with chronic lung disease: possible role of right ventricular hypertrophy. J Am Coll Cardiol 1985; 5: 1302-1307.

66 Forman MB, Wilson BH, Sheller JR, et al. Right ventricular hypertrophy is an important determinant of right ventricular infarction complicating acute inferior left ventricular infarction. J Am CollCardiol 1987; 10: 1180-1187.

67 Vonk-Noordegraaf A, Marcus JT, Holverda S, et al. Early changes of cardiac structure and function in COPD patients with mild hypoxemia. Chest 2005; 127: 1898-1903.

68 Sabit R, Bolton CE, Fraser AG, et al. Sub-clinical left and right ventricular dysfunction in patients with COPD. Resp Med 2010; 104: 1171-1178.

69 Huttin $\mathrm{O}$, Lemarie J, Di Meglio M, et al. Assessment of right ventricular functional recovery after acute myocardial infarction by 2D speckle-tracking echocardiography. Int J Cardiovasc Imaging 2015; 31: 537-545.

70 Delgado V, Mollema SA, Ypenburg C, et al. Relation between global left ventricular longitudinal strain assessed with novel automated function imaging and biplane left ventricular ejection fraction in patients with coronary artery disease. J Am Soc Echocardiogr 2008; 21: 1244-1250.

71 Antoni ML, Ten Brinke EA, Marsan NA, et al. Comprehensive assessment of changes in left atrial volumes and function after ST-segment elevation acute myocardial infarction: role of two-dimensional speckle-tracking strain imaging. J Am Soc Echocardiogr 2011; 24: 1126-1133.

72 van der Bijl $\mathrm{P}$, Khidir $\mathrm{MJH}$, Leung $\mathrm{M}$, et al. Reduced left ventricular mechanical dispersion at 6 months follow-up after cardiac resynchronization therapy is associated with superior long-term outcome. Heart Rhythm 2018; 15: 1683-1689.

73 Bulluck H, Hammond-Haley M, Fontana M, et al. Quantification of both the area-at-risk and acute myocardial infarct size in ST-segment elevation myocardial infarction using T1-mapping. J Cardiovasc Magn Res 2017; 19: 57.

74 Ersboll M, Valeur N, Andersen MJ, et al. Early echocardiographic deformation analysis for the prediction of sudden cardiac death and life-threatening arrhythmias after myocardial infarction. JACC Cardiovasc Imaging 2013; 6: $851-860$

75 Goedemans L, Abou R, Hoogslag GE, et al. Left ventricular global longitudinal strain and long-term prognosis in patients with chronic obstructive pulmonary disease after acute myocardial infarction. Eur Heart J Cardiovasc Imaging 2019; 20: 56-65.

76 Mangion K, McComb C, Auger DA, et al. Magnetic resonance imaging of myocardial strain after acute ST-segment-elevation myocardial infarction: a systematic review. Circ Cardiovasc Imaging 2017; 10: e006498.

77 Haland TF, Almaas VM, Hasselberg NE, et al. Strain echocardiography is related to fibrosis and ventricular arrhythmias in hypertrophic cardiomyopathy. Eur Heart J Cardiovasc Imaging 2016; 17: 613-621. 
78 Lahousse L, Niemeijer MN, van den Berg ME, et al. Chronic obstructive pulmonary disease and sudden cardiac death: the Rotterdam study. Eur Heart J 2015; 36: 1754-1761.

79 Konecny T, Somers KR, Park JY, et al. Chronic obstructive pulmonary disease as a risk factor for ventricular arrhythmias independent of left ventricular function. Heart Rhythm 2018; 15: 832-838.

80 Meris A, Verma A, Thune JJ, et al. Left atrial remodelling in patients with myocardial infarction complicated by heart failure, left ventricular dysfunction, or both: the VALIANT echo study. Eur Heart J 2009; 30: 56-65.

81 Beinart R, Boyko V, Schwammenthal E, et al. Long-term prognostic significance of left atrial volume in acute myocardial infarction. J Am Coll Cardiol 2004; 44: 327-334.

82 Kubota Y, Asai K, Murai K, et al. COPD advances in left ventricular diastolic dysfunction. Int J Chron Obstr Pulm Dis 2016; 11: 649-655.

83 Antoni ML, ten Brinke EA, Atary JZ, et al. Left atrial strain is related to adverse events in patients after acute myocardial infarction treated with primary percutaneous coronary intervention. Heart 2011; 97: 1332-1337.

84 Nourian S, Hosseinsabet A, Jalali A, et al. Evaluation of right atrial function by two-dimensional speckle-tracking echocardiography in patients with right ventricular myocardial infarction. Int J Cardiovasc Imaging 2017; 33: $47-56$

85 Liu D, Borlotti A, Viliani D, et al. CMR native T1 mapping allows differentiation of reversible versus irreversible myocardial damage in st-segment-elevation myocardial infarction: an OxAMI study (Oxford Acute Myocardial Infarction). Circulation Cardiovasc Imaging 2017; 10: e005986.

86 Neilan TG, Bakker JP, Sharma B, et al. T1 measurements for detection of expansion of the myocardial extracellular volume in chronic obstructive pulmonary disease. Can J Cardiol 2014; 30: 1668-1675. 